\title{
An amyloid lung
}

\author{
W. E. ZUNDEL and A.P. PRIOR ${ }^{1}$ \\ Chest Clinic, Coventry and Warwickshire Hospital, Coventry, and the Group Pathology Laboratory, \\ Lakin Road, Warwick
}

\begin{abstract}
A 55-year-old housewife died from an illness characterized by progressive respiratory incapacity. Changes were confined to the lungs and consisted of a diffuse infiltration by amyloid. No adequate cause was found for this amyloid, and we suggest that this is a case of primary alveolar septal amyloidosis.
\end{abstract}

In this paper we describe the clinical, radiological, and pathological features of an unusual form of amyloid disease of the lung. The nature and complications of amyloid disease have been described by Symmers (1956a, b). Nevertheless yet another case presenting in an unusual form seems to be worth recording.

'Dr. A. P. Prior died on 2 January 1971 whilst visiting Australia

\section{CASE REPORT}

A 55-year-old housewife was first seen as an outpatient in March 1968. In January of that year she had developed a febrile illness which had been accompanied by signs of consolidation at the right base. Although initial treatment with oral antibiotics had resulted in some improvement, she continued to com-

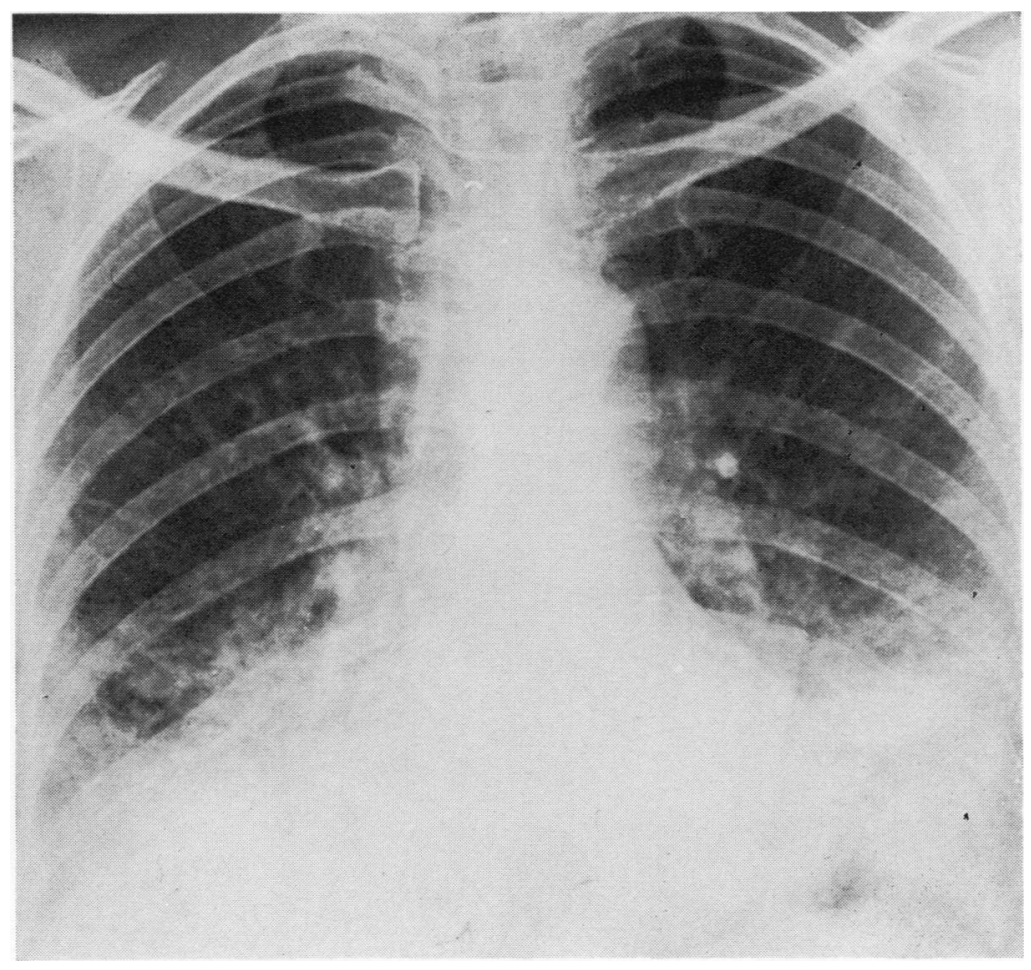

FIG. 1. Chest radiograph showing dense confluent opacities in both lower zones and linear opacities in the upper and middle lung fields. 
plain of lassitude, cough with mucoid sputum, and increasing breathlessness on exertion. There had also been recent loss of weight.

On examination she looked well, and the only abnormal signs were in the respiratory system. Showers of fine and medium crepitations were audible over the lower chest on both sides. A chest radiograph revealed dense confluent opacities in both lower lung fields and profuse linear opacities involving the upper and middle lung fields (Fig. 1). A month later, when the patient had become more breathless, a further radiograph showed that the opacities had increased in profusion. The following investigations were normal: blood count, erythrocyte sedimentation rate (Westergren), liver function tests and plasma proteins, serum electrolytes, and Rose Waaler and RA latex tests. LE cells were not demonstrated. Electrophoresis showed an increase in the alpha 2 globulin fraction. Estimation of serum immunoglobulins revealed a low level of all immunoglobulins: IgG $400 \mathrm{mg} / 100 \mathrm{ml}$, IgM $42 \mathrm{mg} / 100 \mathrm{ml}(60 \%$ of standard), IgA $96 \mathrm{mg} /$ $100 \mathrm{ml} \mathrm{(32 \%} \mathrm{of} \mathrm{standard),} \mathrm{IgD} \mathrm{not} \mathrm{detected.} \mathrm{Paper}$ electrophoresis revealed no evidence of a band in the gamma region. Urinalysis was normal. Sputum cultures were non-contributory.

Physiological assessment: FVC $1.2 \quad 1$. (predicted normal 2.85 1.). $\mathrm{FEV}_{1} 1.01$. $\mathrm{FEV}_{1} / \mathrm{FVC} \% 84 \%$, all by Vitalograph dry spirometer. Indirect MBC $38 \mathrm{l} / \mathrm{min}$ (predicted normal $68 \mathrm{l} . / \mathrm{min}$ ); fractional $\mathrm{CO}$ uptake $37 \%$ (predicted normal 53\%); $\mathbf{P C O}_{2} 40.6 \mathrm{mmHg}$
(Campbell Howell rebreathing method). These results suggested a restrictive type of ventilating defect and a defect of gas transfer.

It was at this stage that an open lung biopsy was done. This showed a widespread infiltration by amyloid. This remarkable picture will be described more fully later.

Treatment with prednisolone was started with temporary subjective improvement only and was discontinued after some weeks. She was discharged in August 1968 still breathless and, in fact, able to do less than before.

At home she became incapacitated by breathlessness, and a dry, unproductive cough persisted. She was readmitted to hospital in November, depressed and worried and in worse physical condition than before. There were no fresh clinical features. Serial chest radiographs showed that confluence had extended to involve the midfields and that there was progressive involvement of the upper fields with linear opacities (Fig. 2).

She deteriorated and died in early December 1968.

PATHOLOGY The original biopsy specimen taken early in 1968 showed that the lung architecture was grossly disturbed. A substance which was eosinophilic in sections stained with haematoxylin and eosin expanded and even obliterated alveolar walls. In places it stained purple due to calcification. Accompanying this there was a cellular reaction. This was made up mainly of

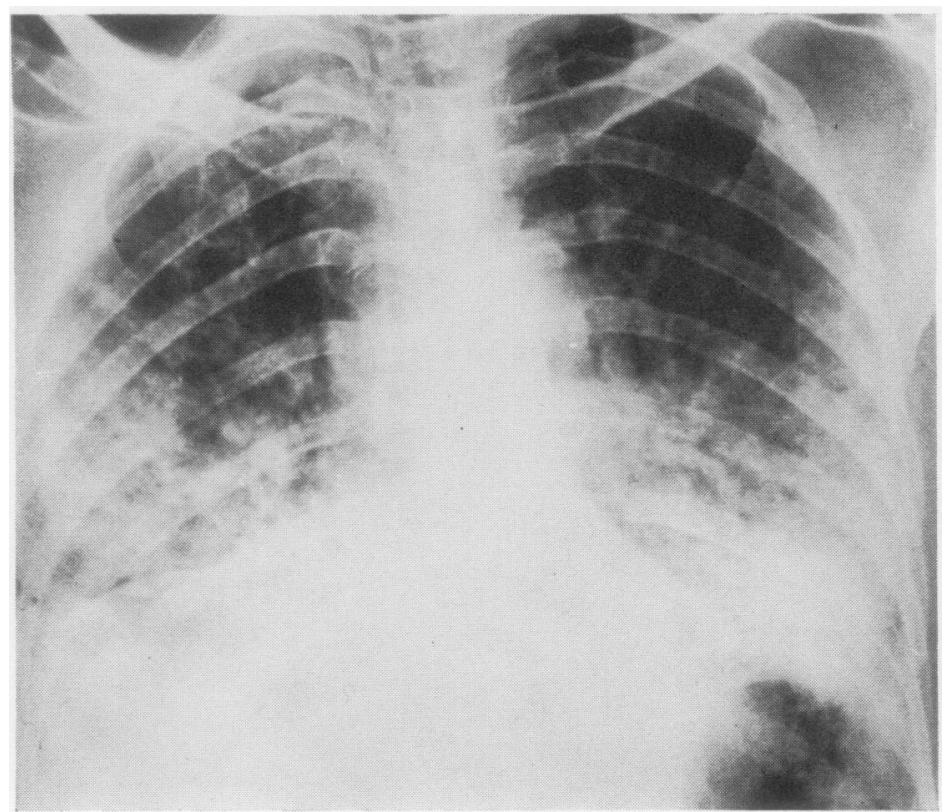

FIG. 2. Chest radiograph eight months after that shown in Figure 1. Note progression of the earlier radiological changes. 


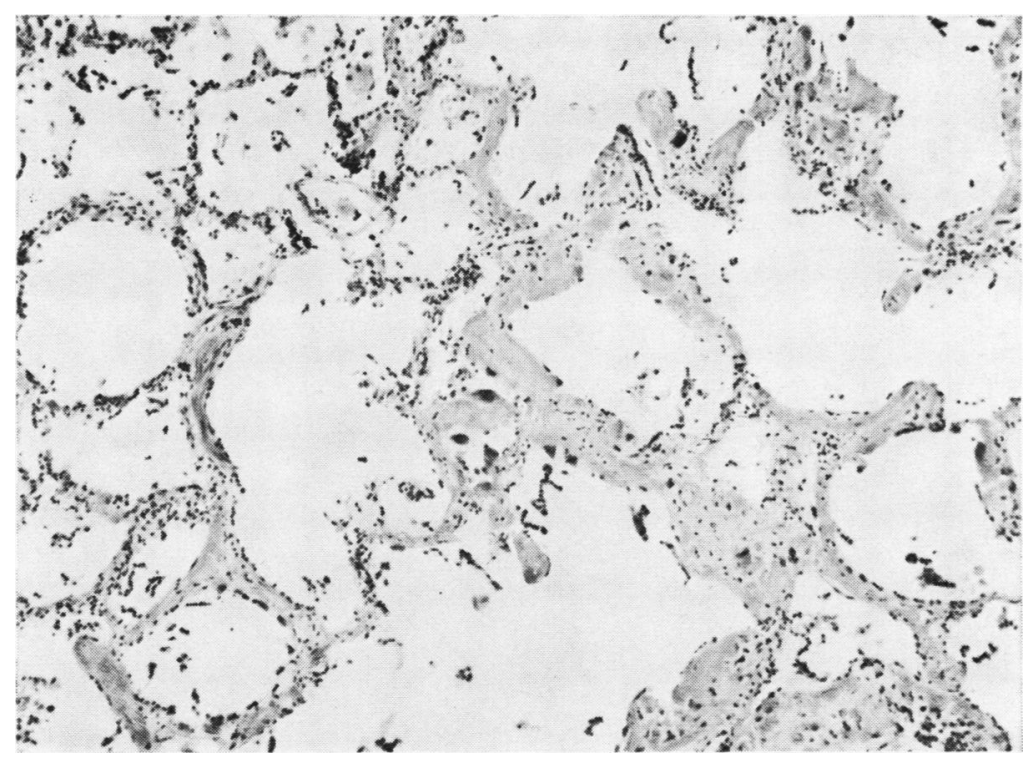

FIG. 3. Amyloid deposit in alveolar septum. H. and E. $\times 36$.

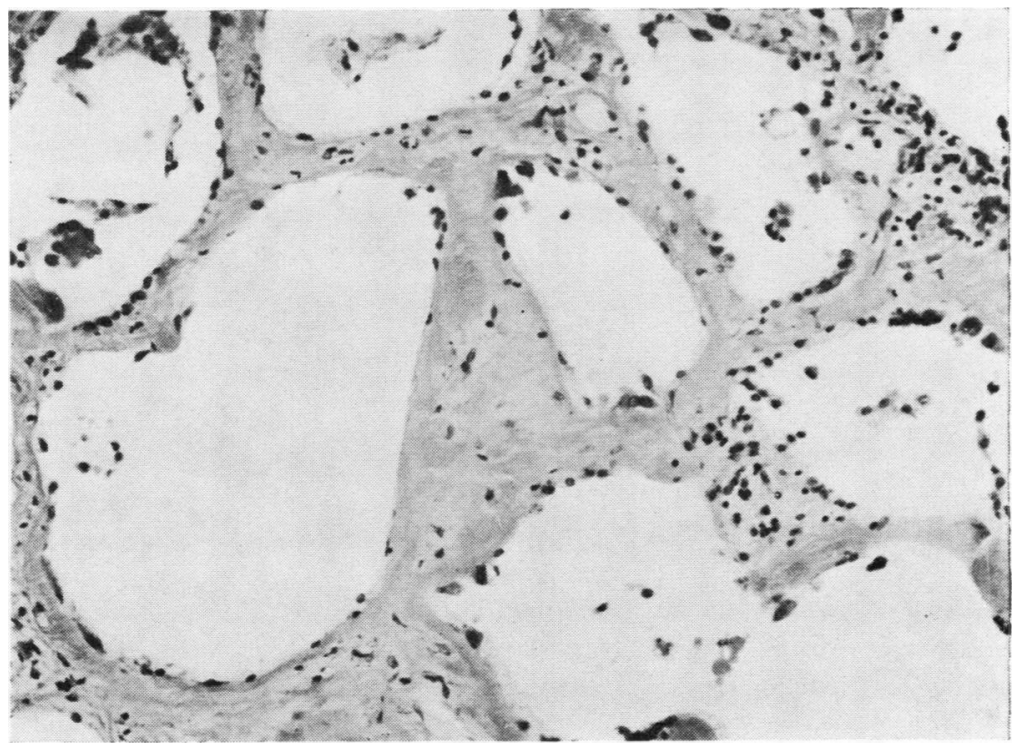

FIG. 4. Deposit in vessel wall and in septum. A pulmonary arteriole can be seen. $H$. and $E . \times 90$. 


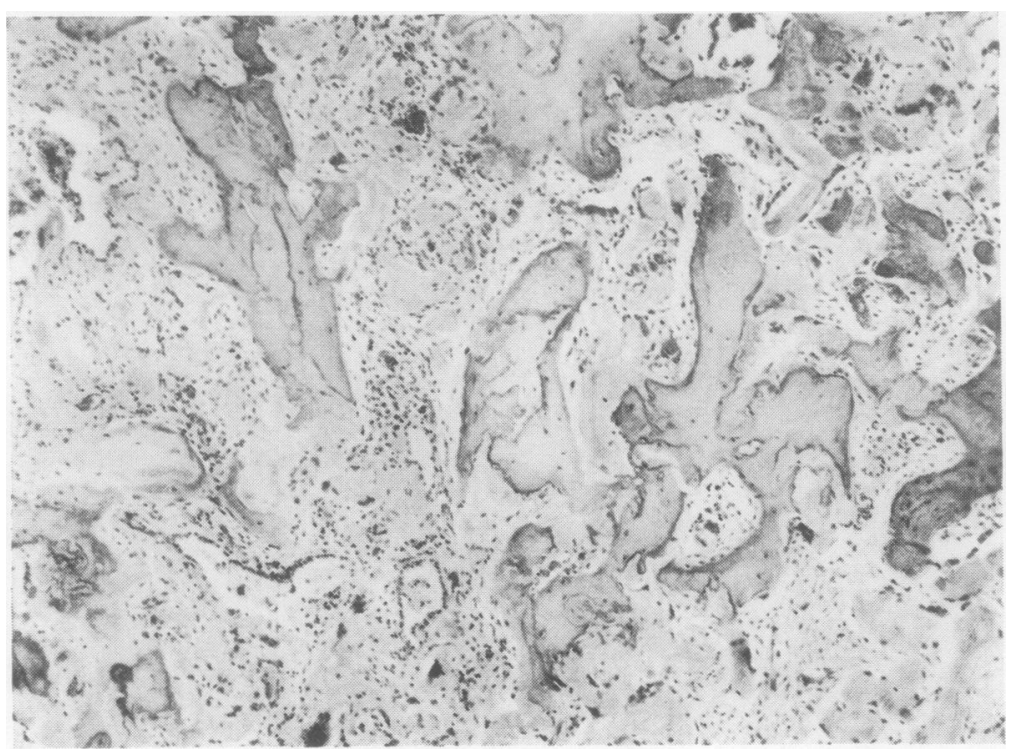

FIG. 5. Cellular reaction and bone formation. $H$. and $E . \times 36$.

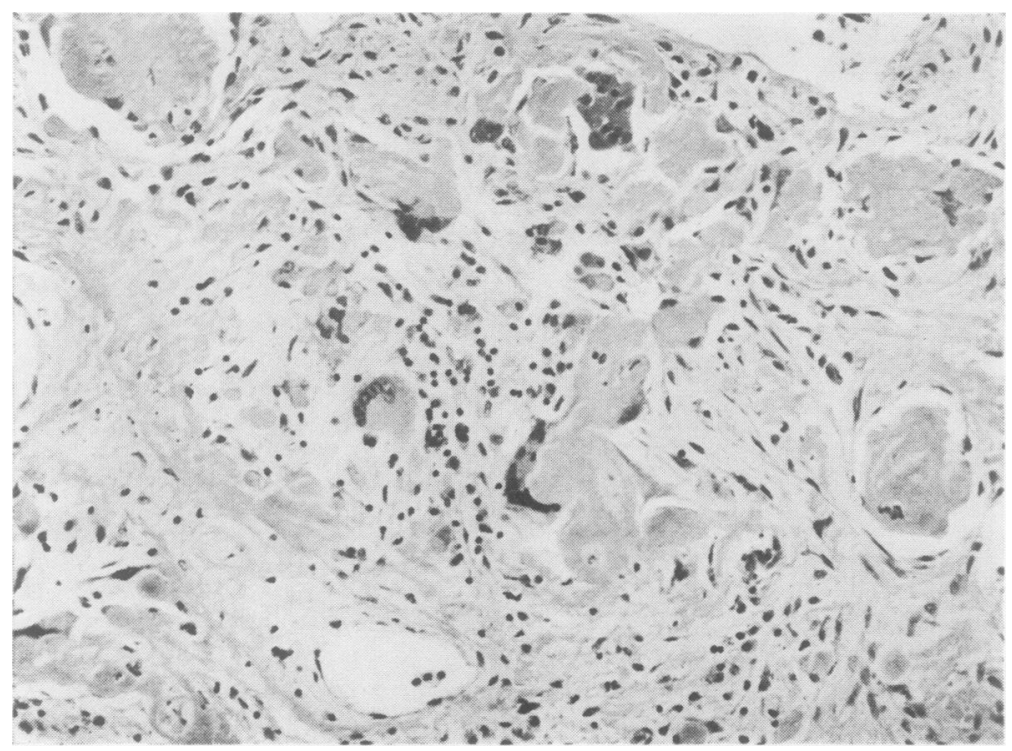

FIG. 6. Cellular reaction to amyloid deposition including large giant cells. $H$. and E. $\times 36$. 


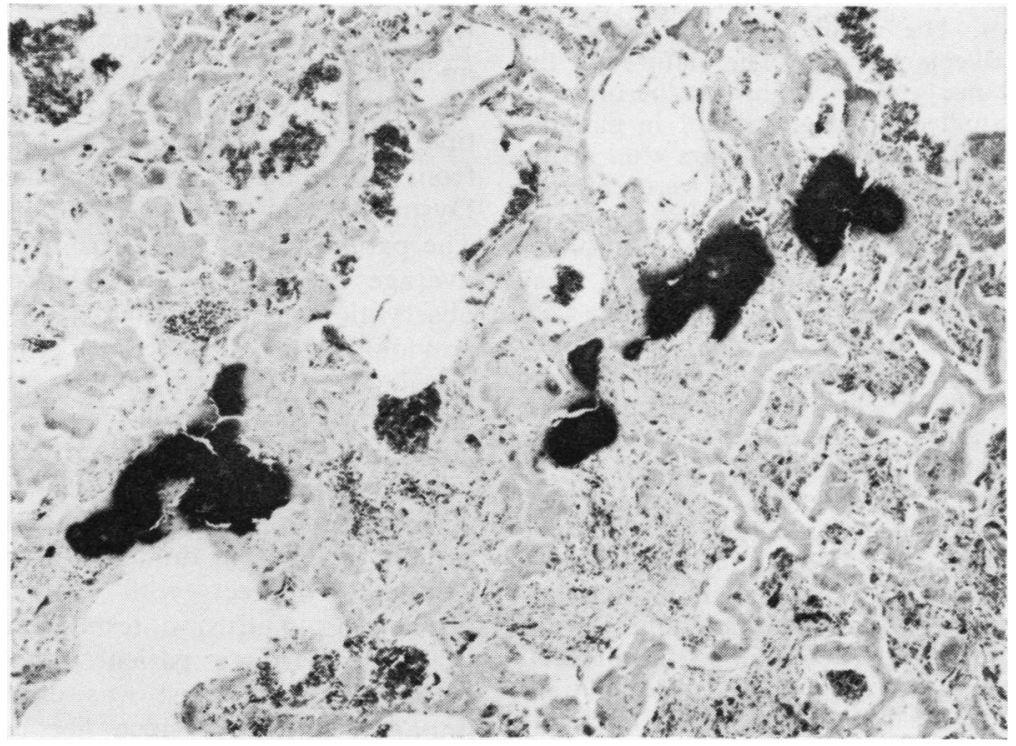

FIG. 7. Amyloid showing bony change. H. and E. $\times 90$.

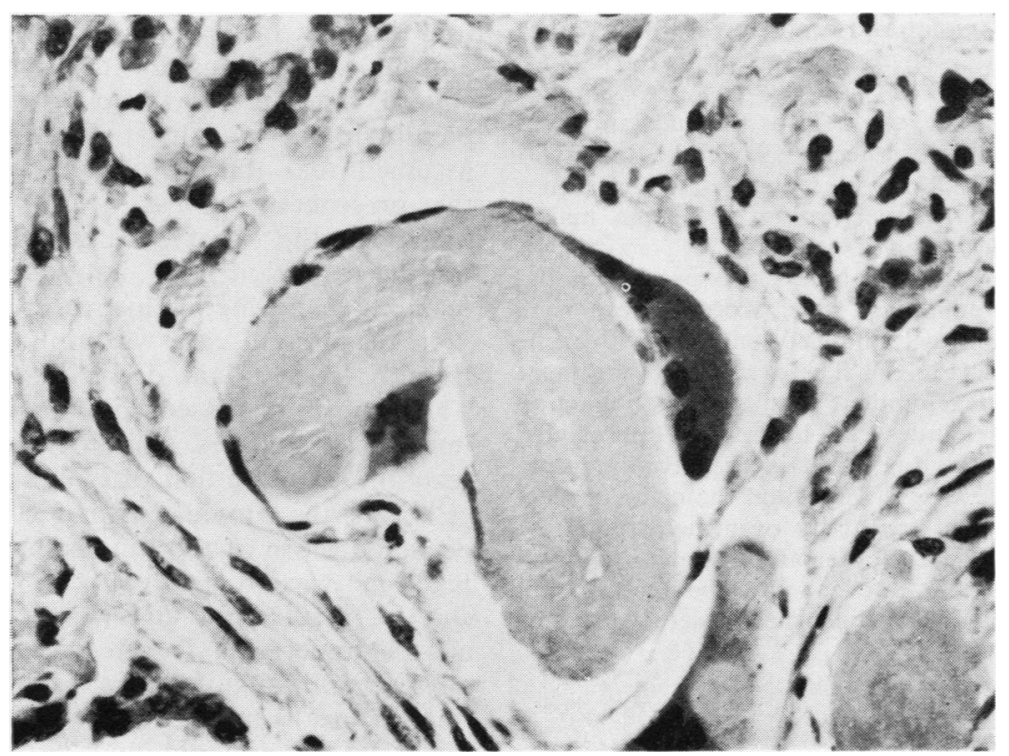

FIG. 8. Giant cell applied to an amyloid deposit. $H$ and $E . \times 225$. 
plasma cells and lymphocytes with some polymorphs and macrophages. There were some large striking multinucleate cells. The cellular reaction was most obvious in the alveolar spaces. The nature of the eosinophilic substance was determined at the time. Its distribution was studied in greater detail in material obtained at necropsy, performed 48 hours after death. Macroscopic and microscopic changes were confined to the lungs.

There were scanty adhesions in the pleural cavities at the bases. The lungs were bulky and heavy. They were infused with formol saline, but they would accept only a little liquid and could not be expanded. They were fixed before cutting. When eventually they were incised the cut surface presented a striking appearance. Very little lung that had been aerated could be detected. The remainder was consolidated to varying degrees of hardness. Some portions showed a bright red colour and these were particularly hard. There, too, the surface was gritty to the touch and to the knife. Darker coloured portions were more resilient.

Microscopically the eosinophilic substance in its earliest form was seen as expansion in the alveolar septa (Fig. 3). It was not seen in blood vessel walls without considerable search, but it could be found (Fig. 4). From the septa it appeared to have spread over the whole parenchyma. It finally appeared as layers of the material in various concentrations with areas of ossification and calcification blotting out the normal architecture (Figs. 5 and 6).

The substance stained acidophilically in haematoxylin and eosin sections and showed khaki to pink with van Gieson. It gave typical metachromasia with crystal violet and bright green fluorescence with thioflavine $T$. There was green birefringence with Congo red and a positive p-dimethylaminobenzaldehyde nitrite reaction. Thus the substance was identified as amyloid (Cooper, 1969). The actual relation of the first deposits to reticulin was not demonstrated, but their position in the septa makes the association very likely.

Cellular reaction to this process was patchy. Sometimes fibrous thickening was seen. More obvious were infiltrations of round cells and polymorphs with some multinucleate cells (Fig. 7). These tended to be large and bizarre. The development of the cellular reaction and of the bony changes can be readily appreciated (Fig. 8). From its starting point in the alveolar septa the process appeared to have excited the cellular reaction by which it was eventually overwhelmed.

A search was made for other amyloid deposits, notably in the gums, the trachea, and the rectum, but such were not found. All the usual viscera were surveyed without success.

\section{DISCUSSION}

Six fully documented reports of somewhat similar cases were found in the literature (Bürümcekci, 1938; Sappington, Davie, and Horneff, 1942; Dirkse,
1946; Blasi, Mazza, and Berti, 1963; Candiani, Di Jasi, and Pasetti, 1965; and Bachmann, 1967). In these there were comparable radiographic appearances, but each and every one had amyloid deposits beyond the lungs. At least one suffered from multiple myeloma (Bachmann, 1967) and another from rheumatoid arthritis (Blasi et al., 1963). Dyspnoea and cough were common symptoms. The patients' ages varied from 50 to 69 years, the average being 58 years. This confirms previous observations (Lunzenauer, 1952) that pulmonary amyloidosis usually becomes clinically manifest in people over 50 years of age. Some of the cases had been reported too long ago to have undergone modern lung function tests. In fact, they were done in but two (Blasi et al., 1963, and Candiani et al., 1965). In these the findings were similar to those in our case, showing a restrictive ventilatory defect with little or no airways obstruction. Diffusion tests were apparently not performed. In our patient only a simple carbon monoxide uptake test was used to demonstrate impaired diffusion, since her condition did not allow of more elaborate tests.

The case of Rajan and Kikkawa (1970) appears to be essentially one of cardiovascular amyloidosis with some spread into the pulmonary tissues. As such it is not strictly comparable.

In all of these previous cases great attention was paid in the histological descriptions to amyloid deposits in the blood vessels and the various authors' conclusions that that is where the process started. Attention was also devoted to the cellular picture in the alveoli, and it seems to have been assumed that this cellular pattern resulted from the presence of the amyloid. Various authors dilated on the variety and nature of the cells seen, but the transition from first appearance to cellular reaction is nowhere illustrated.

In the present case we think that amyloid may have been first laid down in the alveolar wall. The deposit increased in size, spread beyond its immediate confines, and then excited a cellular reaction made up first of lymphocytes and plasma cells. As the amyloid expanded and matured it occupied more of the lung substance. A giant-cell reaction was then apparent. As the amyloid showed ossification and calcification it swamped all the underlying features, destroyed the parenchyma, and engulfed the cellular reaction. The final picture is one of a functionless piece of tissue made up of amyloid and bone and with some local cellular response.

Some of the authors of the previous publications have been kind enough to let us see materia 
from the lungs of their cases. In one we were able to confirm that amyloid was present, using histochemical methods which were reasonably specific. In others we agreed that the substance was probably amyloid. In only one were we satisfied that the primary lesion could have been in the alveolar wall, and even in this case involvement of blood vessels was much greater than in ours. In at least one other we formed the opinion that the cellular process could have anteceded the amyloid. In this we thought that it was at least arguable that the primary condition could have been a fibrosing alveolitis or some established condition which had been followed by amyloid change. In yet another we thought that fixation of the tissue had been overlong delayed.

Ossification and calcification of amyloid in the lungs is by no means unknown (Symmers, 1956b). It must, however, be acknowledged that such changes have been part of a generalized amyloidosis. No reasonable explanation of these events is offered or of those where the bone is accompanied by marrow formation.

Diffuse alveolar septal pulmonary amyloidosis, whether occurring on its own or in association with amyloidosis in other organs, is a rare condition and one which leads to an inevitable fatal outcome in a comparatively short period of time. No effective treatment has so far been described. We think it is worth while suspecting this disease when faced with the never easy differential diagnosis of diffuse radiographic pulmonary opacities.
Biopsy seems the only means of making a definitive diagnosis.

The authors thank Dr. A. O. Bech for advice, Dr. T. Wade Evans and Mr. H. D. James for help with the illustrations, and Miss M. Warwick for secretarial assistance.

\section{REFERENCES}

Bachmann, R. (1967). Die diffuse alveolarseptale Lungenamyloidose. Frankfurt Z. Path., 76, 111.

Blasi, A., Mazza, L. Vitali, and Berti, R. (1963). Amiloidosi polmonare diffusa ad originario aspetto miliariforme. Arch. Tisiol., 18 (sez. sci.), 3.

Bürümcekci, K. (1938). Mitteilung eines Falles von atypischer Amyloidose (Paramyloidose). Virchows Arch. path. Anat., 302, 607.

Candiani, G., Di Jasi, W., and Pasetti, B. M. (1965). Amiloidosi polmonare nodulare diffusa. Riv. Anat. pat., 27, 107.

Cooper, J. H. (1969). An evaluation of current methods for the diagnostic histochemistry of amyloid. J. clin. Path., 22, 410.

Dirkse, P. R. (1946). Primary amyloidosis of the lungs. Amer. J. Roentgenol., 56, 577.

Lunzenauer, K. (1952). Über Amyloid-'Tumoren' der Lungen. Frankfurt Z. Path., 63, 519.

Rajan, V. T., and Kikkawa, Y. (1970). Alveolar septal amyloidosis in primary amyloidosis. Arch Path., 89, 521.

Sappington, S. W., Davie, J. H., and Horneff, J. A. (1942). Primary amyloidosis of the lungs. J. Lab. clin. Med., 27, 882.

Symmers, W. St. C. (1956a). Primary amyloidosis: a review. J. clin. Path., 9, 187.

- (1956b). Amyloidosis: Five cases of primary generalized amyloidosis and some other unusual cases. J. clin. Path., 9, 212. 